\title{
Clinical Evaluation of the Safety, Efficacy and Tolerability of Lanthanum Carbonate in the Management of Hyperphosphatemia in Patients with End-Stage Renal Disease
}

This article was published in the following Dove Press journal:

Therapeutics and Clinical Risk Management

\section{Valeria Cernaro (iD \\ Sebastiano Calimeri \\ Alfredo Laudani $(\mathbb{D}$ \\ Domenico Santoro}

Unit of Nephrology and Dialysis, Department of Clinical and Experimental Medicine, University of Messina, Messina, Italy
Correspondence: Valeria Cernaro Unit of Nephrology and Dialysis, Department of Clinical and Experimental Medicine, University of Messina, Via Consolare Valeria N. I, Messina 98124, Italy

Tel/Fax +39.090.2212317

Email valecern82@virgilio.it

\begin{abstract}
Patients with progressive chronic kidney disease (CKD) commonly develop mineral and bone abnormalities and extraskeletal calcifications with following increased cardiovascular risk. A key pathophysiological role is played by hyperphosphatemia. Since diet and dialysis are often insufficient to control serum phosphorus levels, many patients require treatment with phosphate binders. Among them is lanthanum carbonate, an aluminum-free non-calcium-based compound. The present review summarizes the most recent literature data concerning the safety, efficacy and tolerability of lanthanum carbonate in patients with end-stage renal disease and hyperphosphatemia. The drug is taken orally as chewable tablets or powder with only minimal gastrointestinal absorption and resulting reduced risk of tissue deposition and systemic drug interactions. The dissociation of the drug in the acid environment of the upper gastrointestinal tract induces the release of lanthanum ions, which bind to dietary phosphate forming insoluble complexes then excreted in the feces. Even though there is no clear evidence that lowering serum phosphorus levels can improve patient-centered outcomes, a mortality benefit with all phosphate binders, especially non-calcium containing ones, is not excluded. Lanthanum carbonate has been suggested to decrease all-cause mortality but not cardiovascular event rate compared to other phosphate binders. It induces a lower suppression of bone turnover than calcium carbonate and calcium acetate and may improve systolic function and cardiac dimension compared to calcium carbonate. Moreover, the use of lanthanum carbonate has been associated with better nutritional status compared to other phosphate binders, lower risk for hypercalcemia than calciumcontaining binders, and amelioration of mild metabolic acidosis contrary to sevelamer hydrochloride. Main adverse effects include nausea, alkaline gastric reflux, gastric deposition of lanthanum, gastrointestinal obstruction, subileus, ileus, perforation, fecal impaction, and reduction of gastrointestinal absorption of some drugs including statins, angiotensin-converting enzyme inhibitors and some antibiotics such as fluoroquinolones or tetracyclines.
\end{abstract}

Keywords: adverse effects, chronic kidney disease-mineral bone disorder, CKD-MBD, hyperphosphatemia, lanthanum carbonate, phosphate binders

\section{Introduction}

Patients with progressive chronic kidney disease (CKD) commonly show typical alterations in calcium/phosphate, parathyroid hormone (PTH) and vitamin D metabolism with resulting abnormal bone turnover, morphology and strength, greater risk of bone fractures, development of calcifications at the vascular or other soft tissue level, and increased cardiovascular morbidity and mortality. The combination of these biochemical 
and clinical manifestations configures a syndrome defined as CKD-mineral bone disorder (CKD-MBD). ${ }^{1}$

Several factors and processes contribute to CKD-MBD pathophysiology. The first step seems to be the gradual reduction in Klotho expression as kidney function declines. ${ }^{2}$ Klotho is a fibroblast growth factor 23 (FGF23) tissue co-receptor and its decrease induces a progressive peripheral resistance to FGF23, whose serum levels consequently rise. FGF23 is secreted by osteoblasts and osteocytes and behaves as a phosphaturic hormone. In particular, it interacts with the FGF-receptor/ $\alpha$-Klotho co-receptor complex thus reducing phosphate reabsorption in the renal proximal tubule; it also induces down-regulation of $1 \alpha$ hydroxylase and up-regulation of 24-hydroxylase with following reduction of 1.25-dihydroxyvitamin-D3 synthesis. ${ }^{3}$ FGF23 increase initially serves as a compensatory mechanism to counteract hyperphosphatemia. Nevertheless, it contributes to CKD-MBD pathogenesis over time due to its ability to decrease 1.25 -dihydroxyvitamin-D3 production. This leads to secondary hyperparathyroidism and to abnormalities in calcium and phosphorus serum levels, with enhanced bone remodeling, extraskeletal calcifications, and further FGF23 release. ${ }^{4}$

As mentioned above, altered mineral metabolism plays a key role in cardiovascular risk in patients with end-stage renal disease (ESRD). Phosphorus, calcium, calciumphosphorus product and PTH levels predict all-cause and cardiovascular mortality. ${ }^{5}$ Furthermore, FGF23 and Klotho dysregulation is associated with cardiac hypertrophy, arteriosclerosis and atherosclerosis. ${ }^{6}$

It follows that a proper clinical management of CKDMBD and of its consequences is essential to preserve bone morphology and physiology, prevent adverse cardiovascular outcomes and reduce overall mortality.

In addition to recommending an appropriate dietary regimen aimed to limit food phosphate intake, the control of serum phosphorus and calcium levels and the prevention and treatment of secondary hyperparathyroidism frequently require a pharmacological approach ${ }^{7}$ that nowadays may take advantage of many classes of drugs acting through different mechanisms. They include: vitamin D sterols (cholecalciferol, calcitriol, ergocalciferol), active vitamin D analogs (alfacalcidol, paricalcitol, doxercalciferol), calcimimetics (cinacalcet, etelcalcetide, evocalcet) and phosphate binders, the latter being divided in calcium-containing (calcium acetate, calcium carbonate) and calcium-free agents (lanthanum carbonate, sevelamer carbonate, sevelamer hydrochloride, bixalomer, sucroferric oxyhydroxide). ${ }^{2}$ In dialysis patients, the management of hyperphosphatemia also benefits from renal replacement therapy. An effective phosphate removal can be achieved by extending session duration, increasing dialysis frequency and switching to high-flux online hemodiafiltration, although the latter has not been confirmed in all clinical trials. ${ }^{8}$

The aim of the present narrative review is to summarize the most recent data about the safety, efficacy and tolerability of lanthanum carbonate in ESRD patients with hyperphosphatemia.

\section{Pharmacokinetics and Mechanism of Action of Lanthanum Carbonate}

Lanthanum carbonate $\left[\mathrm{La}_{2}\left(\mathrm{CO}_{3}\right)_{3}\right]$ (Figure 1) is an aluminum-free non-calcium-based compound used for the treatment of hyperphosphatemia in patients with ESRD since 2004 in the USA and since 2006 in Europe. ${ }^{9,10}$

After being taken as chewable tablets or oral powder, the drug is only minimally absorbed from the gastrointestinal tract $^{11,12}$ with a consequently low absolute bioavailability, which was equal to $0.00127 \pm 0.0008 \%$ in a randomized Phase I study involving healthy individuals. ${ }^{13}$ The small amount reaching the circulation almost completely binds to plasma proteins. Then, free lanthanum concentrations are very low with resulting reduced risk of tissue deposition. The poor absorption by the gut also explains the scarce probability of systemic drug interactions. ${ }^{14}$ However, lanthanum carbonate can reduce gastrointestinal absorption of some drugs, among which fluoroquinolones, due to its ability to form chelates with these molecules. ${ }^{15}$ More than $99 \%$

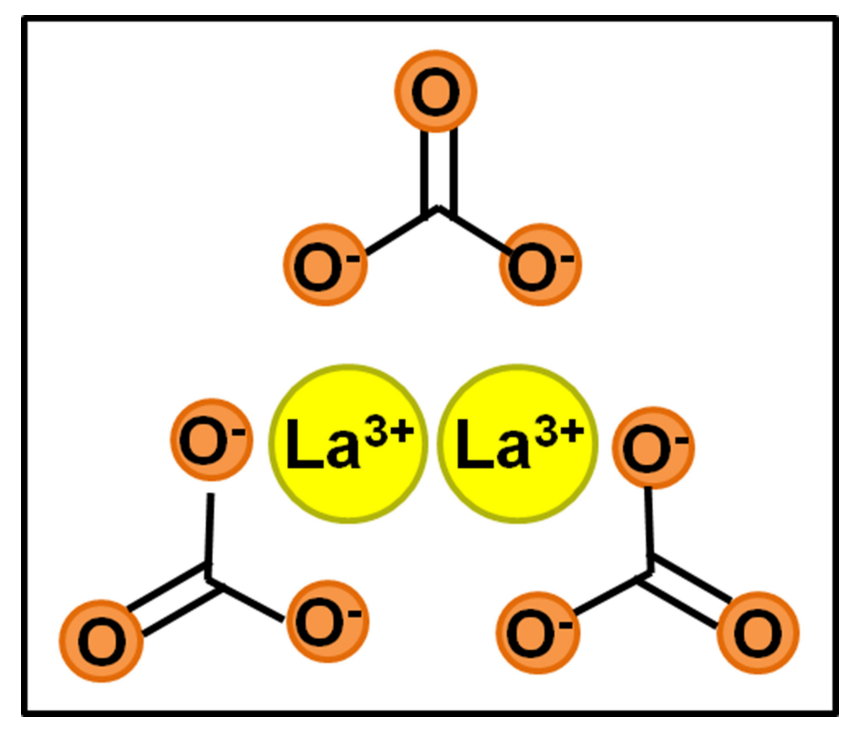

Figure I Schematic representation of lanthanum carbonate structure $\left[\mathrm{La}_{2}\left(\mathrm{CO}_{3}\right)_{3}\right]$. 
of lanthanum carbonate is excreted in the feces. ${ }^{12}$ The minimal renal excretion accounts for the low risk of systemic accumulation in ESRD patients, which show a lanthanum exposure profile similar to that of subjects with normal kidney function. ${ }^{14}$

The drug works by dissociating itself in the acid environment of the upper gastrointestinal tract with release of lanthanum ions $\left(\mathrm{La}^{+}\right)$, which bind to dietary phosphate resulting in insoluble lanthanum-phosphate complexes and net decrease in serum phosphate levels. ${ }^{9,16}$ The action of all phosphate binders depends on gastric $\mathrm{pH}$ that influences both salt dissolution rate and binding reaction between ion and phosphate. ${ }^{17}$ The gastric $\mathrm{pH}$ corresponding to an optimal phosphate binder activity for lanthanum carbonate is $3-5$, but the drug maintains the ability to carry out its function at $\mathrm{pH} 1-7 . .^{18,19}$

\section{Comparative Studies on Efficacy of Lanthanum Carbonate in Patients with End-Stage Renal Disease}

PubMed database was searched on April 2020 for randomized controlled trials published between 2015 and 2020 using the terms "lanthanum carbonate" and "ckd" or "lanthanum carbonate" and "dialysis" or "lanthanum carbonate" and "hemodialysis" (Figure 2). Articles published in languages other than English were excluded. The main characteristics of the included trials are summarized in Table 1. Meta-analyses, post-hoc analyses and observational studies of interest were also briefly described to provide more complete information.

Numerous studies have assessed the effects of lanthanum carbonate on different endpoints.
Compared to calcium carbonate, lanthanum carbonate has been demonstrated to significantly reduce serum FGF23 and determine a trend of decline in hepcidin values whereas no difference was found between the two groups as regards intact $\mathrm{PTH}$, alkaline phosphatase, vitamin $\mathrm{D}$, fetuin-A, and osteopontin levels in hemodialysis patients. ${ }^{20}$ However, in another study, intact FGF23 levels were lowered by sucroferric oxyhydroxide to a greater extent than lanthanum carbonate despite serum phosphate was similarly reduced in the two groups. ${ }^{21}$

More specifically concerning bone metabolism and pathophysiology, a Japanese study involving incident dialysis patients showed that lanthanum carbonate may prevent low bone turnover compared to calcium carbonate. Indeed, at 18 months, serum osteocalcin concentrations were significantly higher in patients receiving lanthanum carbonate than in those treated with calcium carbonate, and the percentage of low bone turnover, according to a cut-off value of serum bone-specific alkaline phosphatase, was appreciably lesser in the lanthanum carbonate group compared to the calcium carbonate group. ${ }^{22}$ However, sevelamer hydrochloride was able to reduce phosphorus, intact PTH and total alkaline phosphatase serum levels to a greater extent than lanthanum carbonate in patients undergoing hemodialysis, with no significantly different calcium levels between the two groups. ${ }^{23}$ A randomized trial on 120 non-dialysis CKD patients with abnormalities in phosphorus balance compared lanthanum carbonate, calcium acetate and dietary restriction for a period of 1 year. The three interventions similarly reduced bone-specific alkaline phosphatase levels, indicating an improvement in bone turnover, but they did

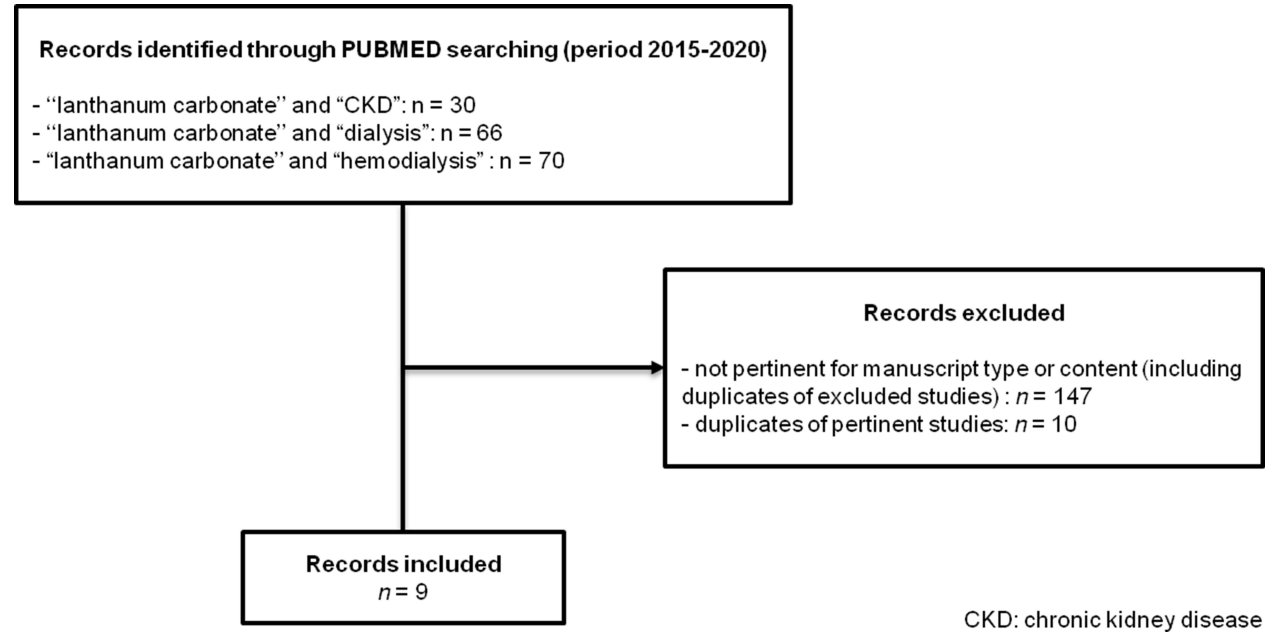

Figure 2 Flow chart of selection of randomized controlled trials. 


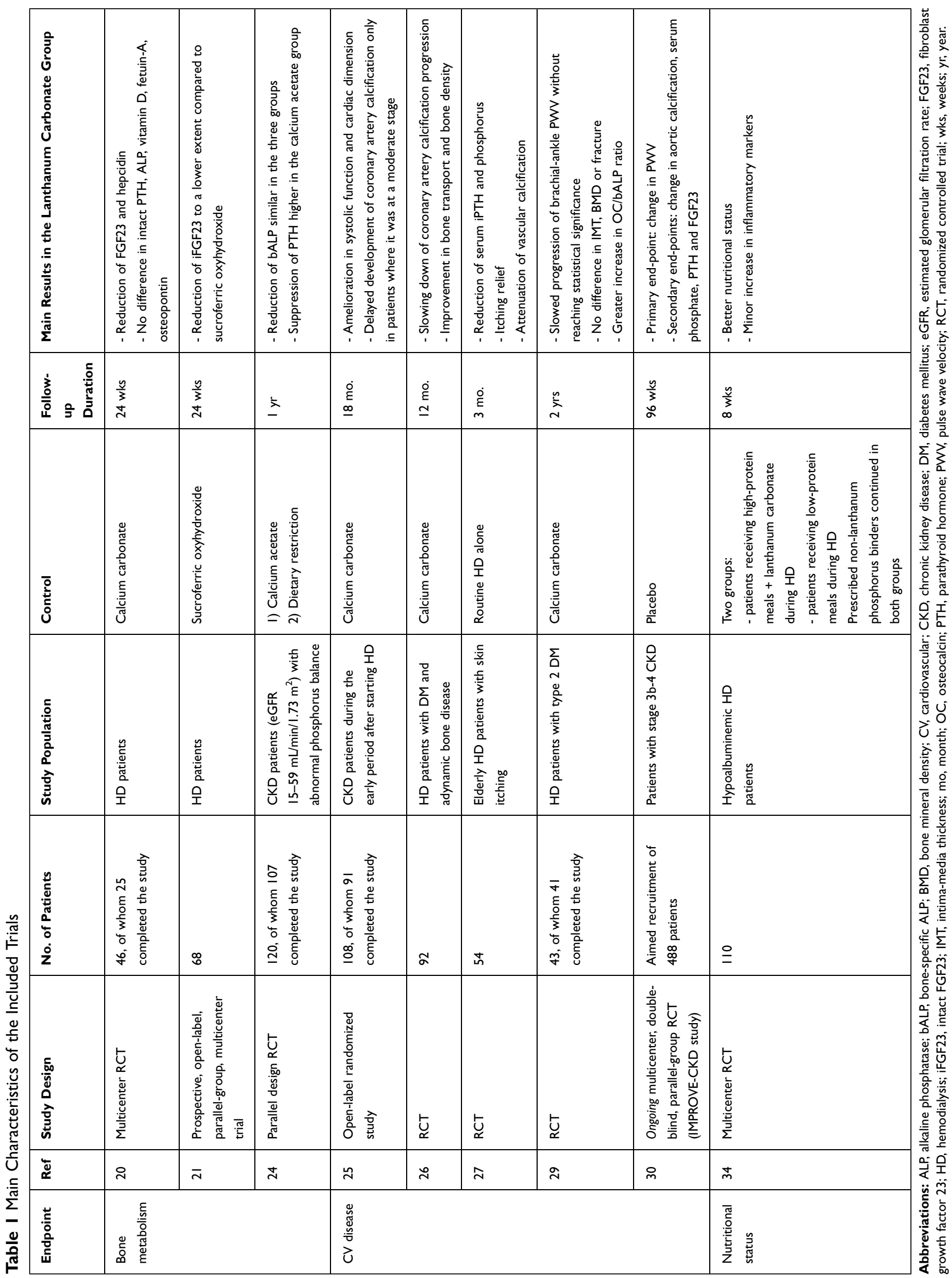


not significantly influence other biochemical or vascular parameters. $^{24}$

Given the association of hyperphosphatemia with cardiovascular disease and all-cause mortality, phosphatelowering drugs are expected to positively influence clinical outcomes and improve prognosis of patients with ESRD.

The impact on cardiovascular calcifications of phosphate binders in general and of lanthanum carbonate in particular is controversial. A randomized open-label study on CKD patients examined the effects of lanthanum carbonate on the progression of coronary artery calcifications and cardiovascular abnormalities compared to calcium carbonate during the early period after starting renal replacement therapy. The use of lanthanum carbonate was associated with amelioration in systolic function and cardiac dimension. Moreover, it delayed the development of coronary artery calcification but only in patients where it

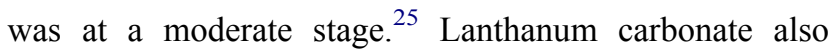
slowed down coronary artery calcification progression in hemodialysis patients with diabetes and adynamic bone disease compared to calcium carbonate, ${ }^{26}$ and reduced itching and abdominal aortic calcification in elderly dialysis $^{\text {patients. }^{27}}$

Nevertheless, no difference was found on the progression of cardiac valvular calcification between lanthanum carbonate and calcium carbonate 18 months after hemodialysis initiation compared to baseline. ${ }^{28}$

Wada et al reported a potentially reduced progression of brachial-ankle pulse wave velocity in diabetic hemodialysis patients treated with lanthanum carbonate for 2 years but the difference with the group receiving calcium carbonate was not statistically significant. ${ }^{29}$

Interesting data concerning the effects of lanthanum carbonate on cardiovascular outcomes in patients with stage $3 \mathrm{~b}$ 4 CKD could emerge from the IMpact of Phosphate Reduction On Vascular End-points (IMPROVE)-CKD study, a double-blind, randomized placebo-controlled parallel-group trial that will assess pulse wave velocity after 96 weeks of lanthanum carbonate therapy versus placebo. ${ }^{30}$

A network meta-analysis including 77 randomized clinical trials (12,562 participants), mostly conducted in dialysis patients, evaluated the impact of phosphate binders containing sevelamer, colestilan, bixalomer, lanthanum, iron compounds, calcium, nicotinic acid and calcium plus magnesium on mortality and other outcomes. All drugs reduced serum phosphorus concentrations to a greater extent than placebo, with iron-based agents proving to be the most effective ones. Trials were generally of short duration and no class of binders demonstrated to decrease mortality or cardiovascular complications compared to placebo. Additionally, lanthanum and sevelamer were associated with a significantly lower risk for hypercalcemia than calcium-containing phosphate binders. ${ }^{31}$ More recently, a meta-analysis of nine randomized controlled trials overall involving 2813 patients on maintenance hemodialysis examined the effect of lanthanum carbonate on all-cause mortality compared to other phosphate binders (calcium acetate, calcium carbonate, and sevelamer). All-cause mortality was significantly lower in patients treated with lanthanum carbonate but the cardiovascular event rate and serum phosphorus levels did not differ between the two groups. Lanthanum carbonate also decreased the risk of hypercalcemia. ${ }^{32}$

Some studies have focused on other peculiar aspects of CKD that may benefit from lanthanum carbonate therapy.

In a cohort study involving chronic hemodialysis patients treated with lanthanum carbonate and other phosphate binders, those receiving lanthanum showed a better nutritional status compared to controls even though serum phosphorus decrease was similar in the two groups. This suggests that the use of phosphate binders and, in particular, of lanthanum carbonate may reduce the need for dietary phosphate restriction with consequent increase in protein intake and improvement in nutritional status. ${ }^{33}$ Similar results had been achieved in a previous randomized controlled trial that demonstrated a better nutritional status, expressed by a rise in serum albumin, as well as a minor increase in inflammatory markers while controlling phosphorus levels in patients receiving high-protein meals during dialysis associated with lanthanum carbonate compared to those receiving low-protein meals. ${ }^{34}$

Interestingly, it has been observed that phosphate binders may influence acid-base balance due to the presence in their molecules of constituents having acidotic or alkalotic properties. Also hyperphosphataemia plays a role, contributing to the condition of metabolic acidosis that is typical of CKD patients. Aluminum-containing and calcium-based binders (calcium carbonate and calcium acetate) partly compensate metabolic acidosis through different mechanisms whereas sevelamer hydrochloride favors metabolic acidosis because it binds phosphate ions in exchange of chloride, which is then buffered by bicarbonate. Lanthanum carbonate contains an alkali and has been demonstrated to increase serum bicarbonate concentration so improving metabolic acidosis. ${ }^{35,36}$ 


\section{Comparative Studies on Safety and Tolerability of Lanthanum Carbonate in Patients with End-Stage Renal Disease}

Different studies regarding the safety of lanthanum carbonate have been conducted over the years, analyzing and comparing it with similar drugs used in the treatment of hyperphosphatemia in patients with ESRD. ${ }^{37-39}$ In all considered works, it is highlighted that this drug represents an excellent therapeutic choice for the lower number of side effects and the greater long-term tolerability. In particular, Hutchinson and colleagues in 2016 published an overview on the safety profile of lanthanum carbonate during a period of 10 years, showing that there is still no evidence of adverse safety outcomes in patients with ESRD. ${ }^{12}$

The purpose of many studies was to evaluate the safety of the drug with respect to the potential effects on the gastrointestinal tract, on bone and liver metabolism, and the possible interactions with other drugs commonly used in ESRD.

Among the possible contraindications to the use of lanthanum carbonate, there is the presence of gastrointestinal diseases such as active peptic ulcer, ulcerative colitis, or Crohn disease. Gastrointestinal involvement has been carefully evaluated in several studies. The already cited network meta-analysis of randomized trials by Palmer and colleagues ${ }^{31}$ showed that lanthanum carbonate is associated with an increased risk of nausea compared to iron-based and calcium-based binders, whereas constipation was more frequent with sevelamer compared to calcium, lanthanum and iron. The use of lanthanum carbonate also seems to induce more frequent and longer lasting periods of alkaline gastric reflux, probably due to more prolonged dissolution time and higher production of $\mathrm{CO}_{2}$ compared to sevelamer hydrochloride and sevelamer carbonate. ${ }^{17}$ Furthermore, numerous cases of gastric deposition of lanthanum have been described in dialysis patients; it is defined as "gastric lanthanosis" and is characterized by endoscopic brightwhite spots and histological eosinophilic histiocytes. ${ }^{40,41}$ In this regard, Yamada and colleagues reported the case of a 70-year-old man with ESRD due to diabetic nephropathy on hemodialysis and treated with lanthanum carbonate $1500 \mathrm{mg} /$ day and lansoprazole $30 \mathrm{mg} /$ day. After finding alterations of the gastric mucosa by routine esophagogastroduodenoscopy, a biopsy was performed and the histological examination showed the presence of groups of cells containing amphophilic fine granular material, identified as histiocytes after positive staining for CD68. Since the patient had been receiving lanthanum carbonate therapy for about 5 years, a histiocyte-mediated phagocytosis of lanthanum was hypothesized; the detection of phosphorus and lanthanum in the interstitium and histiocyte cytoplasm confirmed the suspected diagnosis. ${ }^{42}$ Treatment with lanthanum carbonate has been also associated with severe gastrointestinal complications including obstruction, perforation, subileus, ileus, and fecal impaction. One of the instructions to reduce the risk of serious adverse gastrointestinal events is to completely chew the tablets before swallowing them. ${ }^{43}$

The therapeutic action against hyperphosphatemia represents one of the principal characteristics of phosphate binders, especially for the prevention and treatment of CKD-MBD. The safety profile of lanthanum carbonate was therefore assessed to analyze its relationship with bone metabolism, with most adverse events mainly related to the use of different binders from lanthanum carbonate. ${ }^{2,44}$ Goto and colleagues evaluated the effects of the drug on bone markers and bone mineral density in patients new to hemodialysis, showing that patients undergoing lanthanum carbonate therapy had a minor percentage of low bone turnover compared to the group treated with calcium carbonate. ${ }^{22}$ This had been also previously reported in 2008 by Malluche and colleagues through bone histological assessment. ${ }^{45}$ The influence of phosphate binders on vitamin D metabolism also shows that lanthanum carbonate is not associated with changes regarding any of the metabolites, while other binders lead to reduced serum levels of 1.25dihydroxyvitamin-D3 and 24.25-dihydroxyvitamin-D3, that are related to negative consequences in $\mathrm{CKD} .{ }^{46}$

The link of lanthanum carbonate with the liver is very important since the hepatobiliary system represents its way of excretion. ${ }^{12}$ For this reason, it should be used with caution in patients presenting biliary obstruction or hepatic impairment, because its elimination may be reduced. However, as evidenced by several trials and works over the years, there are no significant negative correlations nor the onset of liveradverse events associated with long-term therapy. ${ }^{12,39}$

Finally, it has been shown that the simultaneous administration of lanthanum carbonate with other drugs usually prescribed to patients with $\mathrm{CKD}$, such as angiotensin-converting enzyme inhibitors, statins or antibiotics (tetracyclines or fluoroquinolones), could decrease their bioavailability. ${ }^{15,43}$ This is mainly related to its ability of binding to drugs with anionic groups. Nevertheless, none of the drug interaction studies were performed with the maximum recommended therapeutic dose of lanthanum carbonate. 


\section{Use of Lanthanum Carbonate: From Current Guidelines to Clinical Practice}

Patients with CKD and reduced renal phosphate excretion may present hyperphosphatemia. Higher serum phosphorus levels, in the context of abnormalities in mineral homeostasis, bone turnover and mineralization and vascular calcifications, predict worsened cardiovascular and all-cause mortality outcomes, both in non-dialysis and in dialysis populations. ${ }^{47}$ Then, it is needed to reduce serum phosphorus concentrations and this can be achieved by restricting intake and/or increasing extrarenal phosphate removal. However, there is still scarce evidence that lowering serum phosphate can improve patientcentered outcomes, as also highlighted by the Kidney Disease
Improving Global Outcomes (KDIGO) CKD-MBD Guidelines updated in 2017. ${ }^{48}$ On the other hand, existing data do not exclude that treatment could be beneficial in terms of mortality reduction. ${ }^{49}$

The updated KDIGO guidelines on CKD-MBD management ${ }^{48}$ suggest starting phosphate binder therapy in patients with CKD G3a-G5D and progressively or persistently elevated serum phosphate concentrations (recommendation 4.1.5), although this is still based on weak clinical evidence. Many drugs are available to counteract mineral metabolism abnormalities in patients with ESRD. Lanthanum carbonate belongs to the class of calcium-free phosphate binders and its main clinical characteristics are summarized in Table 2. Data from literature show that this drug may provide a survival

Table 2 Clinical Aspects of Treatment with Lanthanum Carbonate

\begin{tabular}{|c|c|}
\hline \multicolumn{2}{|c|}{ Key Points and Main Findings from Literature on Lanthanum Carbonate } \\
\hline $\begin{array}{l}\text { Class } \\
\text { Composition }\end{array}$ & $\begin{array}{l}\text { Aluminum-free non calcium-based phosphate binder } \\
\mathrm{La}_{2}\left(\mathrm{CO}_{3}\right)_{3}\end{array}$ \\
\hline Mechanism of action & $\begin{array}{l}\text { Dissociation in the upper gastrointestinal tract with following binding of released lanthanum ions to dietary } \\
\text { phosphate to form insoluble complexes, then excreted in the feces } 9,16\end{array}$ \\
\hline Pharmacological features & $\begin{array}{l}\text { - Formulations: chewable tablets, powder } \\
\text { - Route of administration: oral } \\
\text { - Gastrointestinal absorption: minimal }\left.\right|^{12} \\
\text { - Absolute bioavailability: low (about } 0.00127 \pm 0.0008 \%)^{13} \\
\text { - Excretion: }>99 \% \text { in feces; }<1 \% \text { in the urine }{ }^{12}\end{array}$ \\
\hline Hard endpoints & $\begin{array}{l}\text { - Scarce evidence that therapeutic approaches aiming to lower serum phosphate can improve patient- } \\
\text { centered outcomes but a mortality benefit with all phosphate binders, in particular non-calcium con- } \\
\text { taining compounds, is not excluded }{ }^{48,49} \\
\text { - Decrease in all-cause mortality but not in cardiovascular event rate compared to other phosphate } \\
\text { binders, in particular, calcium-based compounds }{ }^{32,33}\end{array}$ \\
\hline Soft endpoints & $\begin{array}{l}\text { - Low suppression of bone turnover compared to calcium carbonate and calcium acetate } \\
\text { - Decrease in serum FGF23 levels and trend of decline in hepcidin levels }{ }^{20} \\
\text { - Systolic function and cardiac dimension significantly improved compared to calcium carbonate } \\
\text { - Lesser progression of coronary artery calcification compared to calcium carbonate } \\
\text { - Better nutritional status compared to other phosphate binders } \\
\text { - Lower risk for hypercalcemia than calcium-containing phosphate binders }{ }^{31} \\
\text { - Potential contribution to the correction of mild metabolic acidosis by increasing serum bicarbonate } \\
\text { concentrations as opposed to sevelamer hydrochloride }{ }^{35,36}\end{array}$ \\
\hline Adverse effects & $\begin{array}{l}\text { - Gastrointestinal tract: nausea, alkaline gastric reflux, gastric deposition of lanthanum, gastrointestinal } \\
\text { obstruction, subileus, ileus, perforation, fecal impaction }{ }^{17,31,40-43} \\
\text { - Reduced gastrointestinal absorption and decreased bioavailability of simultaneously administered drugs } \\
\text { (angiotensin-converting enzyme inhibitors, statins, antibiotics such as tetracyclines or } \\
\text { fluoroquinolones) })^{15,43} \\
\text { - Scarce probability of systemic drug interactions }{ }^{14} \\
\text { - No significant data for liver damage }\end{array}$ \\
\hline Possible contraindications & - Gastrointestinal diseases (active peptic ulcer, ulcerative colitis, Crohn disease) ${ }^{43}$ \\
\hline
\end{tabular}

Abbreviation: FGF23, fibroblast growth factor 23 . 
benefit compared to other phosphate binders, especially calcium-based ones. ${ }^{32,33}$ Nonetheless, potential effects of phosphate-lowering therapies on hard endpoints have not been unequivocally proven. Probably this occurs because hyperphosphatemia appears late compared to the first abnormalities of CKD-MBD, but starting phosphate binders when phosphorus serum levels are still normal would expose patients to adverse effects from these drugs for many years. In particular, as described above, the use of lanthanum carbonate can be associated with a variety of gastrointestinal adverse effects and requires caution especially in patients with pre-existing diseases at this level. Even more noteworthy, despite the established association between high phosphate and mortality, binder therapy in patients with CKD stage G3b or G4 and normal phosphate levels did not lead to the expected results in a recent trial. Indeed, the treatment only minimally decreased serum phosphate, had no effect on FGF23 and increased coronary calcifications compared to placebo. ${ }^{50}$ Moreover, there is no evidence that a reduction in dietary phosphorus intake is able to improve clinical outcomes in patients with CKD G3a to $\mathrm{G} 4,{ }^{48}$ even though the gradual increase in the production of phosphaturic hormones (FGF23, PTH) precisely originates from the need to maintain serum phosphorus within the normal range. ${ }^{2}$ This compensatory mechanism is so efficient that hyperphosphatemia appears only when glomerular filtration rate is severely impaired, but the progressive increase in FGF23 and PTH concentrations is associated with higher cardiovascular risk. ${ }^{5,6}$ Notwithstanding these pathophysiological assumptions, the lack of strong evidence from clinical trials has induced to focus the treatment only on patients with overtly increased phosphate levels, ${ }^{48}$ emphasizing the need for future studies to evaluate the real effectiveness of hyperphosphatemia prevention in patients with CKD stage G3a to G5D at high risk for CKD-MBD, for example, based on FGF23 concentrations.

\section{Conclusions}

Treatment of hyperphosphatemia due to $\mathrm{CKD}$ with lanthanum carbonate is effective and well tolerated. The drug may induce a decrease in all-cause mortality compared to calcium-based phosphate binders but further studies are required to strengthen the evidence of a real survival benefit from lanthanum carbonate and other binders, especially in patients at higher risk.

\section{Disclosure}

The authors report no conflicts of interest in this work.

\section{References}

1. Moe SM, Drüeke T, Lameire N, Eknoyan G. Chronic kidney disease-mineral-bone disorder: a new paradigm. Adv Chronic Kidney Dis. 2007;14(1):3-12. doi:10.1053/j.ackd.2006.10.005

2. Cernaro V, Santoro D, Lacquaniti A, et al. Phosphate binders for the treatment of chronic kidney disease: role of iron oxyhydroxide. Int J Nephrol Renovasc Dis. 2016;9:11-19. doi:10.2147/IJNRD.S78040

3. Tan SJ, Cai MM. Is there a role for newer biomarkers in chronic kidney disease-mineral and bone disorder management? Nephrology. 2017;22(Suppl 2):14-18. doi:10.1111/nep.13015

4. Cernaro V, Santoro D, Lucisano S, Nicocia G, Lacquaniti A, Buemi M. The future of phosphate binders: a perspective on novel therapeutics. Expert Opin Investig Drugs. 2014;23(11):1459-1463. doi:10.1517/13543784.2014.962652

5. Young EW, Albert JM, Satayathum S, et al. Predictors and consequences of altered mineral metabolism: the dialysis outcomes and practice patterns study. Kidney Int. 2005;67(3):1179-1187. doi:10.1111/j.1523-1755.2005.00185.x

6. Memmos E, Papagianni A. New insights into the role of FGF-23 and Klotho in cardiovascular disease in chronic kidney disease patients. Curr Vasc Pharmacol. 2020;18. doi:10.2174/1570161118666200420102100

7. Bellinghieri G, Santoro D, Savica V. Emerging drugs for hyperphosphatemia. Expert Opin Emerg Drugs. 2007;12 (3):355-365. doi:10.1517/14728214.12.3.355

8. Floege J. Phosphate binders in chronic kidney disease: a systematic review of recent data. J Nephrol. 2016;29(3):329-340. doi:10.1007/ s40620-016-0266-9

9. Albaaj F, Hutchison AJ. Lanthanum carbonate (Fosrenol): a novel agent for the treatment of hyperphosphataemia in renal failure and dialysis patients. Int $J$ Clin Pract. 2005;59(9):1091-1096. doi:10.1111/j.1368-5031.2005.00592.x

10. Aaseth J, Bjorke-Monsen AL. Lanthanum carbonate a new phosphate binding drug in advanced renal failure. Curr Med Chem. 2018;25 (1):113-117. doi:10.2174/0929867324666170509125840

11. Savica V, Calò LA, Monardo P, Santoro D, Bellinghieri G. Phosphate binders and management of hyperphosphataemia in end-stage renal disease. Nephrol, Dialysis, Transpl. 2006;21(8):2065-2068. doi:10.1093/ ndt/gfl289

12. Hutchison AJ, Wilson RJ, Garafola S, Copley JB. Lanthanum carbonate: safety data after 10 years. Nephrology. 2016;21(12):987-994. doi:10.1111/nep. 12864

13. Pennick M, Dennis K, Damment SJ. Absolute bioavailability and disposition of lanthanum in healthy human subjects administered lanthanum carbonate. J Clin Pharmacol. 2006;46(7):738-746. doi: $10.1177 / 0091270006289846$

14. Damment SJ, Pennick M. Clinical pharmacokinetics of the phosphate binder lanthanum carbonate. Clin Pharmacokinet. 2008;47 (9):553-563. doi:10.2165/00003088-200847090-00001

15. How PP, Fischer JH, Arruda JA, Lau AH. Effects of lanthanum carbonate on the absorption and oral bioavailability of ciprofloxacin. Clin J Am Soc Nephrol. 2007;2(6):1235-1240. doi: $10.2215 / \mathrm{CJN} .01580407$

16. Behets GJ, Verberckmoes SC, D'Haese PC, De Broe ME. Lanthanum carbonate: a new phosphate binder. Curr Opin Nephrol Hypertens. 2004;13(4):403-409. doi:10.1097/01.mnh.0000133973.86816.e9

17. Coppolino G, Lucisano S, Rivoli L, et al. Sevalamer hydrochloride, sevelamer carbonate and lanthanum carbonate: in vitro and in vivo effects on gastric environment. Therapeutic Apheresis Dialysis. 2015;19(5):471-476. doi:10.1111/1744-9987.12305

18. Fricker SP. The therapeutic application of lanthanides. Chem Soc Rev. 2006;35(6):524-533. doi:10.1039/b509608c

19. He A, Zhou F, Ye F, et al. Preparation and characterization of lanthanum carbonate octahydrate for the treatment of hyperphosphatemia. $J \quad$ Spectroscopy. 2013;2013:593636. doi: $10.1155 / 2013 / 593636$ 
20. Chang YM, Tsai SC, Shiao CC, et al. Effects of lanthanum carbonate and calcium carbonate on fibroblast growth factor 23 and hepcidin levels in chronic hemodialysis patients. Clin Exp Nephrol. 2017;21 (5):908-916. doi:10.1007/s10157-016-1362-9

21. Otsuki T, Utsunomiya K, Moriuchi M, et al. Effect of sucroferric oxyhydroxide on fibroblast growth factor 23 levels in hemodialysis patients. Nephron. 2018;140(3):161-168. doi:10.1159/000490903

22. Goto K, Goto S, Fujii H, Watanabe K, Kono K, Nishi S. Effects of lanthanum carbonate on bone markers and bone mineral density in incident hemodialysis patients. J Bone Miner Metab. 2019;37 (6):1075-1082. doi:10.1007/s00774-019-01018-8

23. Zhou T, Li H, Xie W, Lin Z. A meta-analysis of phosphate binders lanthanum carbonate versus sevelamer hydrochloride in patients with end-stage renal disease undergoing hemodialysis. Afr Health Sci. 2018;18(3):689-696. doi:10.4314/ahs.v18i3.27

24. Kovesdy CP, Lu JL, Wall BM, et al. Changes with lanthanum carbonate, calcium acetate, and phosphorus restriction in CKD a randomized controlled trial. Kidney International Reports. 2018;3 (4):897-904. doi:10.1016/j.ekir.2018.03.011

25. Fujii H, Kono K, Nakai K, et al. Effects of lanthanum carbonate on coronary artery calcification and cardiac abnormalities after initiating hemodialysis. Calcif Tissue Int. 2018;102(3):310-320. doi:10.1007/ s00223-017-0347-3

26. Zhang C, Wang S, Zhao S, Zhang X. Effect of lanthanum carbonate on coronary artery calcification and bone mineral density in maintenance hemodialysis patients with diabetes complicated with adynamic bone disease: A prospective pilot study. Medicine. 2017;96 (45):e8664. doi:10.1097/MD.0000000000008664

27. Wang XH, Zhang X, Mu CJ, et al. Effects of lanthanum carbonate on vascular calcification in elderly maintenance hemodialysis patients. J Huazhong Univ Sci Technolog Med Sci. 2015;35(4):508-513. doi:10.1007/s11596-015-1461-y

28. Watanabe K, Fujii H, Kono K, Goto S, Nishi S. Comparison of the effects of lanthanum carbonate and calcium carbonate on the progression of cardiac valvular calcification after initiation of hemodialysis. BMC Cardiovasc Disord. 2020;20(1):39. doi:10.1186/s12872-02001343-1

29. Wada K, Wada Y, Uchida HA, Tsuruoka S. Effects of lanthanum carbonate versus calcium carbonate on vascular stiffness and bone mineral metabolism in hemodialysis patients with type 2 diabetes mellitus: a randomized controlled trial. Int J Nephrol Renovasc Dis. 2015;8:111-118. doi:10.2147/IJNRD.S90791

30. Lioufas N, Toussaint ND, Pedagogos E, et al. Can we IMPROVE cardiovascular outcomes through phosphate lowering in CKD? Rationale and protocol for the impact of phosphate reduction on vascular end-points in chronic kidney disease (IMPROVE-CKD) study. BMJ Open. 2019;9(2):e024382. doi:10.1136/bmjopen-2018-024382

31. Palmer SC, Gardner S, Tonelli M, et al. Phosphate-binding agents in adults with CKD: a network meta-analysis of randomized trials. Am j Kidney Diseases. 2016;68(5):691-702. doi:10.1053/j.ajkd.2016.05.015

32. Wang F, Lu X, Zhang J, Xiong R, Li H, Wang S. Effect of lanthanum carbonate on all-cause mortality in patients receiving maintenance hemodialysis: a meta-analysis of randomized controlled trials. Kidney Blood Press Res. 2018;43(2):536-544. doi:10.1159/000488700

33. Komaba H, Kakuta T, Wada T, Hida M, Suga T, Fukagawa M. Nutritional status and survival of maintenance hemodialysis patients receiving lanthanum carbonate. Nephrol, Dialysis, Transpl. 2019;34 (2):318-325. doi:10.1093/ndt/gfy090

34. Rhee CM, You AS, Koontz Parsons T, et al. Effect of high-protein meals during hemodialysis combined with lanthanum carbonate in hypoalbuminemic dialysis patients: findings from the FrEDI randomized controlled trial. Nephrol, Dialysis, Transpl. 2017;32 (7):1233-1243. doi:10.1093/ndt/gfw323
35. Thet Z, Win AK, Pedagogos E, Beavis J, Crikis S, Nelson C. Differential effects of phosphate binders on pre-dialysis serum bicarbonate in end-stage kidney disease patients on maintenance haemodialysis. $B M C$ Nephrol. 2013;14:205. doi:10.1186/1471-2369-14-205

36. Beaubien-Souligny W, Bezzaoucha S, Pichette V, et al. The effect of lanthanum carbonate on metabolic acidosis in patients with chronic kidney disease stage IV, V and V-D. Int Urol Nephrol. 2015;47 (7):1165-1171. doi:10.1007/s11255-015-1003-3

37. Hutchison AJ, Maes B, Vanwalleghem J, et al. Long-term efficacy and tolerability of lanthanum carbonate: results from a 3-year study. Nephron Clin Pract. 2006;102(2):c6171. doi:10.1159/000088932

38. Finn WF. Lanthanum carbonate versus standard therapy for the treatment of hyperphosphatemia: safety and efficacy in chronic maintenance hemodialysis patients. Clin Nephrol. 2006;65(3):191-202. doi: $10.5414 /$ CNP65191

39. Hutchison A, Whelton A, Thadhani R, et al. Long-term mortality and bone safety in patients with end-stage renal disease receiving lanthanum carbonate. Nephron. 2018;140(4):265-274. doi:10.1159/000492603

40. Shitomi Y, Nishida H, Kusaba T, et al. Gastric lanthanosis (lanthanum deposition) in dialysis patients treated with lanthanum carbonate. Pathol Int. 2017;67(8):389-397. doi:10.1111/pin.12558

41. Hoda RS, Sanyal S, Abraham JL, et al. Lanthanum deposition from oral lanthanum carbonate in the upper gastrointestinal tract. Histopathology. 2017;70(7):1072-1078. doi:10.1111/his.13178

42. Yamada T, Oyama T, Tomori A, et al. Distribution of lanthanum carbonate in the gastric mucosa confirmed by electron microscopy with a magnified endoscopy: a case report and literature review. Clin J Gastroenterol. 2019.

43. Highlights of prescribing information. FOSRENOL (lanthanum carbonate) chewable tablets, for oral use. US Food and Drug Administration. Availabla from: http://www.accessdata.fda.gov/drugsatfda_docs/label/ 2016/021468s020,204734s001lbl.pdf. Accessed May 17, 2020.

44. Sprague SM. A comparative review of the efficacy and safety of established phosphate binders: calcium, sevelamer, and lanthanum carbonate. Curr Med Res Opin. 2007;23(12):3167-3175. doi:10.1185/030079907X242719

45. Malluche HH, Mawad H, Monier-Faugere MC. Effects of treatment of renal osteodystrophy on bone histology. Clin J Am Soc Nephrol. 2008;3(Suppl 3):S157163. doi:10.2215/CJN.02500607

46. Ginsberg C, Zelnick LR, Block GA, et al. Differential effects of phosphate binders on vitamin D metabolism in chronic kidney disease. Nephrol, Dialysis, Transpl. 2020;35(4):616-623. doi:10.1093/ndt/gfaa010

47. Tentori F, Blayney MJ, Albert JM, et al. Mortality risk for dialysis patients with different levels of serum calcium, phosphorus, and PTH: the Dialysis Outcomes and Practice Patterns Study (DOPPS). Am j Kidney Diseases. 2008;52(3):519-530. doi:10.1053/j.ajkd.2008.03.020

48. Ketteler M, Block GA, Evenepoel P, et al. Executive summary of the 2017 KDIGO chronic kidney disease-mineral and bone disorder (CKD-MBD) guideline update: what's changed and why it matters. Kidney Int. 2017;92(1):26-36. doi:10.1016/j.kint.2017. 04.006

49. Palmer SC, Teixeira-Pinto A, Saglimbene V, et al. Association of drug effects on serum parathyroid hormone, phosphorus, and calcium levels with mortality in CKD: a meta-analysis. Am j Kidney Diseases. 2015;66(6):962-971. doi:10.1053/j.ajkd.2015.03.036

50. Block GA, Wheeler DC, Persky MS, et al. Effects of phosphate binders in moderate CKD. J Am Soc Nephrol. 2012;23 (8):1407-1415. doi:10.1681/ASN.2012030223 


\section{Publish your work in this journal}

Therapeutics and Clinical Risk Management is an international, peerreviewed journal of clinical therapeutics and risk management, focusing on concise rapid reporting of clinical studies in all therapeutic areas, outcomes, safety, and programs for the effective, safe, and sustained use of medicines. This journal is indexed on PubMed Central, CAS,
EMBase, Scopus and the Elsevier Bibliographic databases. The manuscript management system is completely online and includes a very quick and fair peer-review system, which is all easy to use. Visit http://www.dovepress.com/testimonials.php to read real quotes from published authors.

Submit your manuscript here: https://www.dovepress.com/therapeutics-and-clinical-risk-management-journal 